\title{
Effects of newborn screening of cystic fibrosis on reported maternal behaviour
}

\author{
Carol Boland, Norman L Thompson
}

\begin{abstract}
Screening for cystic fibrosis is highly controversial. Concerns have been expressed that newborn screening may cause mothers, who had considered their child to be healthy before diagnosis, to overprotect their child. Some critics of screening also suggest that a period of delay from onset of symptoms to diagnosis may help a mother adjust to the reality of the child's lethal condition. This study compared the strength of overprotective child rearing attitudes of 29 mothers whose children were screened (13 had symptomatic children and 16 asymptomatic children) with the attitudes of 29 mothers whose children were diagnosed after the onset of symptoms. Results indicate that newborn screening had not increased a mother's tendency to overprotect her child with cystic fibrosis and in some cases the tendency had decreased. Further, delay in diagnosis when screening was not conducted usually caused mothers considerable personal distress.
\end{abstract}

Several procedures have been developed in the last two decades that identify the presence of cystic fibrosis in newborn infants. The implementation of these procedures in newborn screening programmes has been highly controversial. Not only are there disagreements about which procedure is the most acceptable, but extensive debate continues concerning the efficacy and ethics of cystic fibrosis screening for newborns. ${ }^{1-15}$

Speculation concerning possible negative psychological consequences of newborn screening have tended to be unspecific. In general the literature on parent-sick child relationships has focused heavily on maternal overprotectiveness. ${ }^{16}$ The present study has therefore sought to address these broad questions from this perspective. Specifically, this study addresses the following questions:

(1) In New South Wales, does newborn screening for cystic fibrosis decrease the time from first maternal concern about cystic fibrosis related symptoms to final confirmation of diagnosis? This time span has been defined as 'diagnostic delay'.

(2) Among mothers who have become concerned by cystic fibrosis related symptoms before diagnosis ('symptomatic children'), is the length of diagnostic delay related to the strength of their maternal protectiveness?

(3) Among mothers who had not become concerned by cystic fibrosis related symptoms before diagnosis ('asymptomatic children'), what effect does absence of observable symptoms at diagnosis have upon the development of overprotective child rearing attitudes?

(4) Among mothers of asymptomatic children, is the strength of any material denial of the child's illness related to the time span from diagnosis to onset of observable symptoms (symptom delay)?

\section{Patients and methods}

SAMPLE SELECTION

Newborn screening for cystic fibrosis commenced in New South Wales in July 1981. Before this date, all first diagnoses in a family resulted from the presentation with symptoms. Since the introduction of screening all children born in this state are screened using immunoreactive trypsin assay, ${ }^{17}$ usually within five days of birth. Assay results are usually known within 10 days of birth. If positive, a second blood sample is sought and a second immunoreactive trypsin assay is conducted, usually within three weeks of birth. Sweat tests are then conducted to confirm diagnosis. Arrangements are made for the child with cystic fibrosis to attend one of four cystic fibrosis clinics in the state.

The medical records of all children with cystic fibrosis born in New South Wales from July 1977 to March 1985 and treated at cystic fibrosis clinics showed 71 families who satisfied the following criteria:

- Only one child with cystic fibrosis in the nuclear or extended family,

- Cystic fibrosis was not immediately diagnosed at birth,

- No other familial experience of chronic or life threatening illness or accident in the child's nuclear family,

- All children in the family shared the same natural mother,

- No deaths had occurred in the child's nuclear family and none in the extended family of either parent within the last 12 months,

- Before diagnosis, parents were unaware of their possibility of having a child with cystic fibrosis.

All mothers were approached to participate in the study. Only two mothers did not reply, while five declined. During subsequent interviews, two mothers had insufficient understanding of English to participate successfully. Another mother was unable to attend because of transport delays. Between the initial approach and eventual interview, the family circumstances of three mothers changed sufficiently to disqualify them. The final study therefore involved 
58 mothers, which represents $82 \%$ of the population as described above.

Mothers were divided into three groups based on their experience of the diagnostic process. The non-screened group comprised 29 mothers of children diagnosed after the onset of symptoms. All these children were born before the beginning of newborn screening.

The screened symptomatic group contained 13 mothers of screened children. These mothers had already become concerned about their child's cystic fibrosis related symptoms before both the first hint and final diagnosis of cystic fibrosis.

The screened asymptomatic group consisted of 16 mothers who did not suspect that their child was affected until the first hint of problems during the screening process.

All interviews were conducted at the mother's choice of location. Most chose their homes $(n=49)$, some chose the cystic fibrosis clinic $(n=4)$, and others chose the home of friends or other 'neutral' locations $(n=5)$. All interviews lasted between one to two hours and were conducted in private.

\section{MEASUREMENT SCALES}

Three subscales of the Parental Attitude Research Inventory (PARI) ${ }^{18}$ were used to measure protective attitudes, and one subscale was used to measure maternal denial. The PARI has been used extensively with mothers of handicapped children. The subscales 'fostering dependency', 'intrusiveness', and 'excluding outside influences' are related to constructs underlying overprotective behaviour. ${ }^{16}$ High scores on these subscales indicate strong agreement with the overprotective sentiments. A fourth subscale, 'approval of activity', was used as a measure of maternal denial. While this subscale was not designed to measure denial, the items suggest that agreement with such sentiments as, 'Children who do not try hard for success will feel they have missed out on things later on', and, 'Parents should teach their children that the way to get ahead is to keep busy and not waste time', may indicate an unwillingness to acknowledge the more serious long term implications of the disease.

The State Trait Anxiety Inventory (STAI) ${ }^{19}$ was also included because anxiety has also been identified as a good predictor of maternal overprotectiveness. ${ }^{16}$

All scales were administered only after the mother had talked extensively about her child. Each mother was asked to complete the PARI in relation to her cystic fibrosis child only.

\section{Results}

The three groups did not differ significantly on the following variables: mother's age at interview, mother's age at birth of the child, marital status, education, ethnicity, socioeconomic status, religious affiliation and practice, number of children, problems in pregnancy and birth, gestation period, number of miscarriages, and the total numbers of her supporters. The children with cystic fibrosis in each group did not differ significantly in relation to sex, birth order, birth weight, days of hospitalisation per year, and current health rating by the child's paediatrician. Birth weight and days per year of hospitalisation were taken from cystic fibrosis clinic records, and verified with mothers. Each child's paediatrician was asked to rate the current health state of the child on a 10 point likert type scale, with one equalling 'asymptomatic' and 10 equalling 'very serious'.

As expected, children in the non-screened group were significantly older than children in the two screened groups (average ages (months) were non-screened: $105 \cdot 7$, screened symptomatic: $30 \cdot 1$, and screened asymptomatic: $24 \cdot 9$ ). No significant age difference was found between the two screened groups. A systematic age difference between the non-screened and two screened groups is an inevitable, and potentially unfortunate, feature of the present design. Because of the possibility of age related effects, extensive statistical analysis was conducted within the non-screened group (the only group with a sufficient age range to give meaningful results) before finalising the research design. When partial correlation coefficients were used to control for the age of the child, no evidence was found that the child's age was influencing the associations between the dependent and independent variables. This means that the systematic age difference between the screened and non-screened groups was not influencing the results.

\section{(1) SCREENING AND DIAGNOSTIC DELAY}

Because it was obvious that the scores were skewed, log transformation was carried out on the original data. A $t$ test was conducted on the transformed data, ${ }^{20}$ and showed that delay in diagnosis was very much longer in the nonscreened than the screened symptomatic group $(t=44.60, \mathrm{p}<0.001)$. The geometric means for the non-screened and screened symptomatic groups were 115.33 and 21.56 respectively. Table 1 shows the mean age of the children in the three groups and its relation to the diagnostic process.

Table 1 Mean age of child with cystic fibrosis in days at stages in the diagnostic process and number of days delay in confirmation or onset of symptoms

\begin{tabular}{|c|c|c|c|}
\hline & $\begin{array}{l}\text { Non-screened } \\
(n=29)\end{array}$ & $\begin{array}{l}\text { Screened } \\
\text { symptomatic } \\
(n=13)\end{array}$ & $\begin{array}{l}\text { Screened } \\
\text { asymptomatic } \\
(n=16)\end{array}$ \\
\hline $\begin{array}{l}\text { First maternal concern } \\
\text { First hint of diagnoses given to mother } \\
\text { Confirmation of diagnoses given to mother } \\
\text { No of days delay from first concern to confirmation } \\
\text { No of days delay from confirmation to onset of symptoms }\end{array}$ & $\begin{array}{r}84 \\
251 \\
271 \\
187 \\
\end{array}$ & $\begin{array}{l}16 \\
35 \\
49 \\
33 \\
\end{array}$ & $\begin{array}{r}314 \\
34 \\
47 \\
-267\end{array}$ \\
\hline
\end{tabular}


Table 2 Correlation of independent and dependent variables for non-screened group $(n=29)$

\begin{tabular}{|c|c|c|c|c|c|c|c|}
\hline Category & $\begin{array}{l}\text { Anxiety } \\
\text { state }\end{array}$ & $\begin{array}{l}\text { Fostering } \\
\text { dependency }\end{array}$ & $\begin{array}{l}\text { Excluding } \\
\text { outside } \\
\text { influences }\end{array}$ & Intrusiveness & $\begin{array}{l}\text { Birth } \\
\text { weight }\end{array}$ & $\begin{array}{l}\text { Child's age } \\
\text { at first } \\
\text { symptom }\end{array}$ & $\begin{array}{l}\text { Delay in } \\
\text { diagnosis }\end{array}$ \\
\hline $\begin{array}{l}\text { Fostering dependency } \\
\text { Excluding outside influences } \\
\text { Intrusiveness } \\
\text { Birth weight } \\
\text { Child's age at lst symptom } \\
\text { Delay in diagnosis } \\
\text { Current health of child }\end{array}$ & $\begin{array}{r}-0.003 \\
0.116 \\
-0.134 \\
0.001 \\
-0.011 \\
0.145 \\
-0.063\end{array}$ & $\begin{array}{l}0.058 \\
0.532^{* *} \\
0.026 \\
-0.220 \\
-0.338^{*} \\
-0.198\end{array}$ & $\begin{array}{r}0.326 \\
-0.175 \\
0.041 \\
0.124 \\
-0.180\end{array}$ & $\begin{array}{r}-0.367^{*} \\
0.134 \\
-0.172 \\
0.187\end{array}$ & $\begin{array}{l}-0.149 \\
-0.061 \\
-0.209\end{array}$ & $\begin{array}{l}0.634^{* *} \\
0.035\end{array}$ & -0.085 \\
\hline
\end{tabular}

${ }^{*} \mathbf{p}<0.05,{ }^{* *} \mathrm{p}<0.001$.

Table 3 Mean (SD) scores for protectiveness measures for each diagnostic group

\begin{tabular}{|c|c|c|c|c|c|}
\hline & $\begin{array}{l}\text { Non-screened } \\
(n=29)\end{array}$ & $\begin{array}{l}\text { Screened } \\
\text { symptomatic } \\
(n=13)\end{array}$ & $\begin{array}{l}\text { Screened } \\
\text { asymptomatic } \\
(n=16)\end{array}$ & $\begin{array}{l}\text { Univariate } \\
F\end{array}$ & $\begin{array}{l}\text { Pooled } \\
\text { SD }\end{array}$ \\
\hline $\begin{array}{l}\text { Fostering dependency } \\
\text { Excluding outside influences } \\
\text { Intrusiveness } \\
\text { Anxiety state }\end{array}$ & $\begin{array}{l}10 \cdot 79(2 \cdot 82) \\
11 \cdot 07(2 \cdot 29) \\
10 \cdot 28(2 \cdot 37) \\
34 \cdot 93(10 \cdot 29)\end{array}$ & $\begin{array}{c}8 \cdot 69(2 \cdot 14) \\
11 \cdot 15(3 \cdot 83) \\
9 \cdot 38(3 \cdot 52) \\
34 \cdot 44(11 \cdot 17)\end{array}$ & $\begin{array}{l}10 \cdot 25(2 \cdot 18) \\
12 \cdot 06(2 \cdot 29) \\
12 \cdot 06(3 \cdot 62) \\
32 \cdot 44(7 \cdot 53)\end{array}$ & $\begin{array}{l}3 \cdot 136^{*} \\
0 \cdot 672 \\
3 \cdot 055^{*} \\
0 \cdot 3409\end{array}$ & $\begin{array}{l}2 \cdot 52 \\
2 \cdot 85 \\
3 \cdot 04 \\
9 \cdot 83\end{array}$ \\
\hline
\end{tabular}

${ }^{*} \mathrm{p}<0 \cdot 05$.

(2) DIAGNOSTIC DELAY AND MATERNAL OVERPROTECTIVENESS

Statistical analysis involved only the nonscreened group because, as table 1 shows, this was the only group to experience extensive diagnostic delay. Initial analysis showed that only two independent variables were significantly related to scores on some of the four measures of maternal protectiveness. These variables were the child's birth weight, and delay in diagnosis (see table 2).

Because of the large number of correlations involved, canonical correlation analysis was used to investigate whether any one or more combinations of these independent variables were contributing to scores on the four protectiveness measures. The results were not significant $(F 12,159=1 \cdot 045, p>0 \cdot 05)$, which suggests that the significant univariate correlations should be treated with some caution.

\section{(3) ASYMPTOMATIC DIAGNOSIS AND MATERNAI} OVERPROTECTIVENESS

Univariate analyses of variance (ANOVA) were conducted on the four measures of overprotectiveness and all three groups. Mean raw scores for the four measures and results of the analyses are shown in table 3.

Fostering dependency and intrusiveness were the only measures in which significant group differences were found. Mothers in the screened symptomatic group scored significantly lower on the fostering dependency scale, while mothers in the screened asymptomatic group scored significantly higher on the intrusiveness scale.

(4) SYMPTOMS DELAY AND MATERNAL DENIAL

Analysis involved only the screened asymptomatic group. The Pearson product moment correlation coefficient analysis (table 4) showed no significant association between symptom delay and scores on the 'approval of activity' subscale. There also was no significant association between the denial measure and the paediatrician's rating of the child's current health.
Table 4 Correlation coefficients for scores on approval of activity scale with delay in symptoms and current health of child (screened asymptomatic group)

\begin{tabular}{lcc}
\hline $\begin{array}{l}\text { Denial } \\
\text { measure }\end{array}$ & $\begin{array}{l}\text { Delay in } \\
\text { symptoms }\end{array}$ & $\begin{array}{l}\text { Current health } \\
\text { of child }\end{array}$ \\
\hline Approval of activity & $\begin{array}{c}0.358 \\
(\mathrm{p}=\mathbf{0 . 0 8 6})\end{array}$ & $\begin{array}{l}\mathbf{0 . 0 7 8} \\
(\mathrm{p}=0.386) \\
-0.207 \\
(\mathrm{p}=0.221)\end{array}$ \\
\hline Delay in symptoms & - & \\
\hline
\end{tabular}

\section{Discussion}

(1) SCREENING AND DIAGNOSTIC DELAY

The results indicate that in New South Wales newborn screening for cystic fibrosis considerably reduces the time between a mother's first concern for her child's cystic fibrosis related symptoms and confirmation of the diagnosis.

It has been suggested by Phelan that such reductions would only occur in communities where diagnostic procedures and infrastructures were less than ideal. ${ }^{21}$ He suggested further that in Victoria, where screening was not then conducted, few undue delays in diagnosis occur. However, careful inquiries in several Australian states and elsewhere have shown that this is not so. ${ }^{15}$

\section{(2) DIAGNOSTIC DELAY AND MATERNAL} OVERPROTECTIVENESS

Among mothers of children who were not screened for cystic fibrosis, the length of delay between her first concern for the child's health and the final confirmation of diagnosis did not influence the extent to which a mother later felt anxious, wanted to exclude outside influences upon the child, or to know everything the child was thinking. As can be seen in table 2, a mother's desire to foster dependency in her child appears to decrease as length at delay in diagnosis increases. There appears to be no reasonable explanation for this significant association. However, canonical correlation analysis suggests that this apparent significance may in fact be a type I error. A long diagnostic delay did not appear to affect adversely the 
mother-child relationship in regard to overprotectiveness.

Even so, at least short term adverse effects on the mother from diagnostic delay became apparent during the interview. A total of $75 \%$ of mothers of non-screened children and $61 \%$ of mothers of screened symptomatic children volunteered reports of personal distress stemming from medical scepticism. Reluctance on the part of medical professionals to believe the child was sick led to responses from doctors or nurses that ranged from patronising reassurances to indignation at the mother's insistence on a second, third, or fourth opinion. It seemed that the less extreme the symptom the greater the difficulty mothers had in convincing physicians that there was a problem. Even for mothers whose children were blatantly unwell, overcoming scepticism was often not easy. Certainly the only reported long term personal ramification of these experiences was increased cynicism towards medical professionals.

\section{(3) ASYMPTOMATIC DIAGNOSIS AND} OVERPROTECTIVENESS

Anxiety state and excluding outside influence

An absence of observable symptoms at diagnosis did not appear to increase the mother's protectiveness as indicated by anxiety state, or to encourage her to discourage the influence of others on her child.

\section{Fostering dependency}

Mothers of screened symptomatic children expressed significantly less need to foster the dependency of their children by protecting them from life's difficulties and disappointments than mothers of non-screened children. The scores of mothers of screened asymptomatic children fell between these two groups.

The greater agreement of the non-screened group of mothers with these sentiments is difficult to explain, except perhaps on the basis of the inherent differences between the groups in the age of the child. However, as stated earlier, extensive statistical analysis indicated that the systematic age differences inherent in the design were not influencing the results.

An alternative explanation can be found in the mothers' own reports of their experiences. During the time before initial medical scepticism gives way to acknowledgment that the child is sick, mothers of non-screened children reported experiencing a growing sense of fear that their child's deteriorating health was the result of their own incompetence. This phenomenon has also been reported elsewhere. ${ }^{22} 23$

Among the screened symptomatic group, such fears of incompetence had very little time to manifest before diagnosis exonerated the mother. However, among mothers of nonscreened children, these experiences may well have instilled in the mother a greater desire to protect the child from all traumas, however mild, as a way of reassuring herself of her own competence.

The mothers of screened asymptomatic children did not have to run the gauntlet of self doubt because the child appeared healthy to everyone. However, they were in the unique position of believing that the length of time their child remained 'healthy' was virtually their sole responsibility, as they were the main providers of the prophylactic treatment. Why then did these mothers not express stronger needs to protect their children? Perhaps the length of time the child remains symptom free encourages maternal denial of the condition. These mothers may have been caught between two competing responses. The more effectively they protected their child from the disease, the greater the temptation to believe such protection was unwarranted.

\section{Intrusiveness}

Mean scores on the intrusiveness scale for the screened asymptomatic group were very close to those of the non-screened group. Thus absence of symptoms did not appear to increase the extent to which mothers of screened asymptomatic children felt the need to know everything their children were thinking. Mothers of the screened symptomatic children were significantly less likely than the other two groups to agree with intrusive sentiments.

It is possible in this case that age differences between the screened and non-screened groups are influencing these results. Among mothers of the older non-screened children, such a desire to know what her child is thinking may have represented a plausible technique for monitoring the child's emotional well being. Many mothers in this group voluntarily reported concern at how the child would react to learning of the long term implications of the disease.

Regardless of the extent of a mother's desire to know what her child was thinking, in the two screened groups this was not possible as the children were too young. Once again, however, for mothers of screened asymptomatic children, the pressures were different. The period of prophylactic treatment was one in which the ethos of 'always being one step ahead of trouble' may have developed to a greater extent in this group because the mother's belief that the child's continued symptom free health (and hence his longevity) was dependent upon her competence. If so, then a score on the intrusiveness scale equal to that of the non-screened group may reflect a desire to adopt such a strategy rather than reflecting its current use.

The influence of delay in confirmation on this scale is difficult to explain, especially given the comparatively short time involved. Considerable variation exists in the approach used by physicians in first mentioning cystic fibrosis to the mother, and further research, apart from clarifying the results found in this study, could examine the influences that these various approaches have on maternal attitudes.

\section{(4) DELAY IN SYMPTOM ONSET AND MATERNAL} DENIAL

Although the association between symptom delay and the extent to which mothers harbour long term ambitions for their children did not 
reach significance, a larger sample size may result in a significant association.

In addition, all these children received prophylactic treatment in the form of physiotherapy from the mother beginning immediately after diagnosis. It is reasonable to assume that giving this treatment helped to keep the mother more firmly 'grounded' in reality. This also may help to explain why the association between denial and symptom delay failed to reach significance. Again, further research is needed to establish the extent to which prophylactic treatment mediates this relationship.

It should also be noted that six of the seven people declining to participate in the study were mothers of screened children. While the proportion of these who considered their child to be asymptomatic at diagnosis is not known, it is possible that the sample studied may be self selecting on the basis of acceptance of the child's condition and its long term ramifications.

IMPLICATIONS OF THIS STUDY

It would seem that even in communities such as the state of New South Wales with sophisticated and well coordinated diagnostic procedures, undue delays in diagnosis occur when screening is not conducted. These delays do not appear to have had a negative effect on those aspects of the mother-child relationship measured by this study. However, medical scepticism engendered self doubt and self blame during this period, which resulted in a great deal of unnecessary distress for most mothers. In some cases this has led to persisting cynicism and mistrust of the medical profession. Thus screening of newborns, far from having detrimental effects on the mother-child relationship, has in some cases been beneficial. This is particularly true for mothers who have already become concerned for the child's health by the time of diagnosis. It would seem however, that the experiences of mothers of apparently healthy children are qualitatively different, and the possibility remains that prophylactic treatment is acting in some way to nullify any negative effects that might otherwise result.

The authors wish to thank the following people for their assistance in the research: Dr Bridget Wilcken, Oliver Latham Laboratory; cystic fibrosis clinical staff at Westmead Hospital, Laboratory; cystic fibrosis clinical staff at Westmead Hospital, Pydney and the Mater Hospital of Newcastle.

1 Bray P. Erroneous diagnosis of cystic fibrosis psychological aspects. In: Lawson D, ed. Cystic fibrosis: horizons. Proceedings of the 9th International Cys

2 Cassio A, Bernardi F, Piazzi S, et al. Neonatal screening for cystic fibrosis by dried blood spot trypsin assay. Acta Paediatr Scand 1984;73:554-8.

3 David TJ, Phillips BM. Overdiagnosis of cystic fibrosis. Lancet 1982;ii:1204-6.

4 Dodge JA, Ryley HC. Screening for cystic fibrosis. Arch Dis Child 1982;57:774-9.

5 Dodge JA, Ryley HC. Screening for cystic fibrosis. Arch Dis Child 1982;57:317.

6 Farrell PM. Early diagnosis of CF: to screen or not to screen-an important question. Pediatrics 1984;73:115-7.

7 Gitzelman R. Why we should not screen our newborn for CF. Helv Paediatr Acta 1981;36:493-4.

8 Holtzman NA. Routine screening of newborns for cystic fibrosis: not yet. Pediatrics 1984;73:98-9.

9 Mastella G, Pederzini F, Girella E. CF screening policy. Lancet 1984;ii:575-6.

10 Orenstein DM, Boat TF, Stern RC, et al. The effect of early diagnosis and treatment in cystic fibrosis. Am $\mathcal{F}$ Dis Child 1977;131:937-57.

11 Phelan PD. Commentary. Arch Dis Child 1982;57:779-80.

2 Rosenstein BJ. Diagnostic delay in CF. $\mathscr{J} A M A$ 1982;247: 3313.

13 Solnit AJ. The risks of screening. Pediatrics 1976;57:646

14 Sorenson JR, Levy HL, Mangione TW, et al. Parental response to repeat testing of infants with false positive results in a newborn screening program. Pediatrics 1984;73: 183-7.

15 Wilcken B, Towns SJ, Mellis CM. Diagnostic delay in cystic fibrosis. Lessons from newborn screening. Arch Dis Child 1983;58:863-6.

16 Parker G. Parental over protection: a risk factor in psychosocial development. New York: Grune and Stratton, 1983.

17 Wilcken B, Brown ARD, Urwin R, et al. Cystic fibrosis screening by dried blood spot trypsin assay: results in 75,000 newborn infants. $\mathcal{F}$ Pediatr 1983;102:383-7.

18 Schaefer ES, Bell RQ. Development of a parental attitude research instrument. Child Dev 1958;29:339-61.

19 Spielberger CD, Gorsuch RL, Lushene RE. STAI manual for the State-Trait Anxiety Inventory. Palo Alto, California: Consulting Psychologists Press, 1970

20 Ryan TA, Joiner BL, Ryan BF. Minitab handbook. Boston: Prindle Weber and Schmidt, 1985

21 Phelan PD. Screening for cystic fibrosis. In: Meadow R, ed Recent advances in paediatrics. Edinburgh: Churchil Livingstone, 1984.

22 Burton L. The family of sick children. London: Routledge and Kegan Paul, 1975 .

23 Falkman C. Cystic fibrosis: a psychological study of 52 children and their families. Acta Paediatr Scand [Suppl] 1977;269:1-103. 